\title{
BIM技术在建筑工程管理中的应用分析
}

\author{
赵 洁* \\ 菏泽国投建设工程有限公司 山东菏泽 274000
}

\begin{abstract}
摘 要: 现如今, 随着中国城市化进程速度日益加快, 大量农村人口涌向城市, 使得原本就不太充裕的一二线城 市生存空间进一步缩小。人均占地面积的减少, 促使城市开发建设不得不趋于纵向发展, 加大空间利用率, 而原本落 后的建筑工程管理模式, 已经不能满足现在的建设市场需求。本文对BIM技术在建筑工程管理中的应用进行分析。

关键词: BIM技术; 建筑工程; 管理应用
\end{abstract}

DOI: https://doi.org/10.37155/2661-4669-0308-41

\section{Analysis on Application of BIM Technology in Construction Engineering Management}

\author{
Jie Zhao* \\ Heze SDIC Construction Engineering Co., Ltd., Heze 274000, Shandong, China
}

\begin{abstract}
Nowadays, with the acceleration of China's urbanization process, a large number of rural people flock to cities, further narrowing the already insufficient living space in first and second tier cities. The reduction of per capita land area has prompted urban development and construction to tend to vertical development and increase space utilization. The original backward construction project management mode can no longer meet the current construction market demand. This paper analyzes the application of BIM Technology in construction engineering management.
\end{abstract}

Keywords: BIM technology; Construction engineering; Management application

1 BIM 技术的特点

1.1 模拟性

BIM技术在实际应用的过程中具有较高的模拟性, 能够保证建立的模型与真实的事物存在很小差异, 提供模型的 真实性。同时使用BIM技术建立模型, 需要全面的数据信息, 进一步提高了模型的建设水平。该技术能够实现传统模 型建立无法达到的水平，充分发挥该技术的模拟性 ${ }^{[1]}$ 。

\section{2 协调性}

建筑工程施工建设的过程中很多问题的出现与部门之间的交流与沟通不到位有很大的关系。通过合理运用BIM技 术可以有效的加强施工单位各部门之间的交流与沟通。过去建筑工程施工管理的过程中采用传统的管理模式, 施工单 位各个部门之间的信息没有及时传达, 导致施工中出现多种不同的问题。而BIM技术具有较强的协调性, 能够对各个 部门的工作进行统筹安排，保证工作能够协调稳定的进行，进一步提升建筑工程的管理效率。

1.3 可视性

过去建立的建筑工程模型多是 $2 \mathrm{D}$ 模型, 技术人员很难对模型进行调整, 同时不同的技术人员对图纸的理解可能 存在一定的偏差, 导致建筑工程的施工存在很多问题。采用BIM技术可以建立可视化模型, 技术人员通过三维立体模 型, 可以直观地分析出建筑工程存在的问题, 并结合解决问题。同时, 技术人员可以提前了解建筑工程内部结构的特 点, 为后期的施工提供了有价值的参考 ${ }^{[2]}$ 。

*通讯作者: 赵洁, 1975年12月, 女, 汉族, 山东菏泽, 大专, 中级工程师, 菏泽国投建设工程有限公司总工, 研究方向: 建筑工程。 


\section{BIM 技术在建筑工程管理中的应用}

\section{1 决策阶段的应用分析}

建筑工程的立项决策阶段对于建筑工程的施工建设具有重要的意义，根据决策结果施工单位可以制定相关的投 资预案，为后期施工的顺利进行打下基础。通过科学合理的应用BIM技术，管理人员可以获取更加真实可靠的数据信 息。建筑工程投资预案的设立与建筑工程的施工建设环境、建筑工程的所处地理位置等都有很大的关系, 采用传统的 方式，管理人员很难掌握全面的数据信息，导致很多问题得不到妥善的处理 ${ }^{[3]}$ 。

\section{2 设计阶段}

2.2.1 设计前准备

建筑工程设计的过程中设计人员需要做好准备工作, 设计人员需要综合分析施工设计图纸, 并深人施工现场, 综 合了解建筑工程施工现场周边的环境以及气候特点, 并收集地质勘察报告等重要的信息, 全面分析施工现场的水文地 质情况, 为后期地基处理以及其他工序的施工提供参考。设计将收集到的图片信息以及数据信息等录人到BIM共享平 台, 然后对信息进行加工与处理, 为模型的建立提供数据基础, 实现设计方案的优化与创新, 保证建筑工程的设计更 加合理 ${ }^{[4]}$ 。

\section{2 .2 碰撞检查}

过去，在进行建筑工程设计的过程中设计人员往往使用CAD技术进行图纸的设计，然后运用专业知识进行检查与 分析, 但是很难通过CAD设计的图纸进行碰撞问题检查, 导致建筑工程施工的过程中经常遇到多种不同的问题, 影响 建筑工程的整体进度, 还会在很大程度上给建筑工程施工单位带来不可挽回的经济损失。BIM技术的应用解决了CAD 技术应用中存在的问题, 通过可视化的三维立体模型, 结合建筑专业、机电安装等知识进行碰撞检查, 及时发现建筑 模型中存在的问题，及时排查出建筑工程设计中存在隐患，提高设计的安全性。

\subsection{3 安全管理应用}

过去建筑工程施工的过程中安全事故发生的概率非常高, 从而给建筑行业的发展带来极大的阻力。近年来人们开始 认识到安全施工的重要意义, 开始重视安全管理工作的开展。BIM技术的合理应用, 有效地排查出建筑工程设计中存在 的安全隐患，减低建筑工程施工的风险。同时，通过建立三维立体模型，技术人员能够识别出建筑工程的安全隐患。

\subsection{4 根据模拟施工开展安全管理}

采用BIM技术的使用, 技术人员可以模拟建筑工程的施工, 能够及预测出建筑工程施工安全问题发生的概率, 并 及时对施工设计方案的调整提供方便。同时在进行安全事故发生概率预测的过程中, 可以综合对事故进行分析与评 判。例如, 通过建筑工程的模型的建立, 技术人员可以对高空坠落以及塔吊事故进行模拟, 可以做好事故预防措施, 降低事故发生给企业带来的危害。同时, 结合建筑工程的模型, 可以对安全事故进行全面的总结与分析。技术人员结 合建筑工程施工中存在的问题, 梳理出高频发生的事故, 从而警示施工人员提高安全施工的意识。根据施工现场具体 的情况以及施工人员的综合情况，做好安全防范措施。

\subsection{5 安全识别与防护}

通过BIM技术的综合分析，施工单位已经确定了安全事故发生概率大的施工区域，因此，施工人员可以对该区域 进行标记与识别, 在具体施工中加强防护。例如, 在进行临边洞口施工的过程中, 施工人员可以根据洞口的大小以及 位置等信息, 采用安装护栏或者安全网的方式, 加强对洞口的防护, 提高施工的安全, 最大限度保障施工人员的人身 安全。BIM技术的应用可以提高安全防护工作的准确性，保证施工的安全。

\section{3 工程进度管理应用}

\section{1 工程进度预测}

为了保证建筑工程进度预测结果更加准确, 施工单位必须建立三维立体模型。技术人员需要做好数据的实时观 测, 做好模型的优化与创新。技术人员可以根据建筑工程的施工方案对模型进行系统的优化, 从而演练出建筑工程施 工的具体情况, 帮助施工单位制定严谨的进度计划。针对施工进度计划中不合理的部分, 技术人员可以对其进行优化 与改进, 从而实现工程进度预测的准确性提升的目的。从三维立体模型中技术人员可以提高施工设计与施工进度计划 的匹配程度，全面调节施工进度计划，预测出准确科学的施工工期。 


\section{2 工程进度的管理}

通常情况下建筑工程进度管理工作的开展可以从实施控制和动态控制两个不同的方面人手。第一，实时控制。该 控制手段主要是技术人员根据施工现场的具体施工情况, 做好实时监督与管理工作, 保证实际工作情况与施工设计方 案中的预测内容一致, 提高施工进度管理目标的可靠性。如果实际施工与施工目标的偏差比较大, 施工人员应该及时 进行调整。第二, 动态控制。采用BIM技术提高对施工现场动态化管理的力度, 科学合理地开展施工内容, 并加强对 施工进度的控制, 保证施工能够按照施工进度计划进行, 确保施工能够在预计的工期内完成。综合建筑工程施工的实 际情况, 依照建筑设计方案、施工方案的要求, 利用BIM技术构建三维信息模型, 通过动态演示, 为现场人员的对各 个环节工序的管理提供对照。

\section{4 质量管理中的应用}

一般情况下建筑工程的施工建设周期比较长, 施工涉及的施工技术比较多, 为了保证施工整体的质量符合质量标 准, 施工单位必须从多个不同的角度出发, 提高建筑工程的安全性以及功能性、耐久性等。采用BIM技术, 施工人员 可以及时发现施工中存在的问题，综合使用施工技术，保证所有施工细节的质量都符合要求，提高建筑工程整体的质 量。同时，施工单位可以制定可行的工程质量控制目标，为施工的顺利进行提供保障 ${ }^{[3]}$ 。

\section{5 成本控制管理中的应用}

利用BIM技术，通过建立的三维立体模型，施工人员可以及时发现建筑工程中存在的问题，并对其进行调整。有 效地避免了施工过程中出现各种问题，从而降低了建筑工程的整体施工成本。建筑工程施工过程中一旦出现质量问 题, 就会出现二次返工的现象, 这在很大程度上增加了建筑工程施工的整体成本。通过合理的建立模型, 技术人员可 以综合进度监管人员以及物料监管人员等多方面的力量, 对模型进行评估与分析, 结合建筑工程质量、施工的安全以 及施工工期对施工成本进行合理的压缩，从而实现建筑工程成本控制与管理的目标。

\section{6 结束语}

总而言之，建筑工程施工建设的过程中工程管理发挥着巨大的作用，施工单位必须加强对施工管理工作的重视。 随着信息技术的不断发展，建筑工程施工的过程中可以充分引人BIM技术，实现建筑工程施工对高效管理，提高建筑 工程施工建设的整体水平，促进建筑行业的持续发展。

\section{参考文献:}

[1]肖天龙,兰奸,陈斯,等.BIM技术在建筑工程管理中的应用分析[J].现代商贸工业,2019,40(29):198-199.

[2]王占立,严金任任东.BIM技术在现代建筑工程项目管理中的应用研究 [J].住宅与房地产,2019,(33): 144 .

[3]朱小娟.试析BIM技术在建筑工程造价中的应用 [J]. 产业创新研究,2019,(11):249-250.

[4]刘志海.BIM技术在建筑工程施工管理中的应用解析[J].居舍,2019,(11):58.

[5]李斌.BIM技术在建筑工程管理中的应用研究 [J].中华建设,2019,(11):74-75. 